\author{
Eliane Cadoná \\ Pontifícia Universidade Católica do Rio Grande do Sul \\ Marlene Neves Strey \\ Pontifícia Universidade Católica do Rio Grande do Sul
}

\title{
A produção da maternidade nos discursos de incentivo à amamentação
}

\begin{abstract}
Resumo: No presente artigo ${ }^{1}$ discutimos, através de materiais da Campanha da Amamentação, discursos da maternidade, por intermédio das práticas de incentivo ao aleitamento materno. Problematizamos a forma como esses materiais veiculam modos de ser mãe, pai e de como cuidar das crianças. Para a análise dos dados, fizemos uso dos conceitos de discurso e de enunciado de Michel Foucault, tomando-os enquanto ferramentas teórico-metodológicas. Nos materiais, percebemos que a mãe é posicionada como principal responsável pela saúde de seus/as filhos/as, tendo o dever de cuidar deles/as e nutri-los/as. O pai ocupa um papel secundário nessa relação, e a figura do especialista em saúde ganha destaque, na medida em que é posicionado enquanto conhecedor das práticas da amamentação, cabendo à mãe aderir aos seus ensinamentos em prol da saúde da criança.
\end{abstract}

Palavras-chave: maternidade; paternidade; discurso; amamentação.

Copyright (๑) 2014 by Revista Estudos Feministas.

$1 \mathrm{O}$ artigo se desdobra a partir da dissertação de mestrado em Psicologia Social da primeira autora deste texto, defendida no ano de 2010, intitulada 'Amamentar é educar para a vida?!?!' A produção da maternidade contemporânea nas campanhas da amamentação, sob a orientação da Profa. $\mathrm{Dr}^{\mathrm{a}}$. Marlene Neves Strey, na linha de pesquisa "Gênero, gerações e subjetividade".

${ }^{2}$ Maria Cristina Chimelo PAIM e Marlene Neves STREY, 2004.

\section{Introdução}

Muitos discursos veiculados no cotidiano demarcam papéis diferenciados para homens e mulheres, que começam a se configurar desde a infância, num momento em que as crianças aprendem a se comportar conforme padrões estabelecidos, nos quais a menina é relacionada à fragilidade e passividade, e o menino, à força, agressividade e virilidade. Essa diferença também estabelece padrões de desigualdade, nos quais os homens ocupam um papel, muitas vezes privilegiado, em termos de dominação. ${ }^{2}$

Nessas diferenças vivenciadas nas práticas cotidianas, demarcam-se posições que os sujeitos devem ocupar, por intermédio de discursos revestidos por um status de 
${ }^{3}$ Ana Maria COLLING, 2004, p. 18

${ }^{4}$ Judith BUTLER, 1987.

5 BUTLER, 1987, p. 143-144.

${ }^{6}$ Carin KLEIN, 2007.

${ }^{7}$ Dagmar E. MEYER, 2000. 'verdade' incontestável. Essa mesma 'verdade' '[...] torna-se o que constrange o pensamento a pensar de uma determinada maneira, aquilo que, em outros momentos da história, sob outras condições, se pensou ou se pensará de modo diferente". ${ }^{3}$

Para Monique Wittig, a diferença entre os sexos não é nada mais do que uma interpretação, constituída de normas fundadas em um sistema binário de gênero. Quando uma criança nasce, a atenção é voltada aos seus traços anatômicos sexualmente diferenciados, que irão determinar o seu destino social. Dentro desse contexto, Judith Butler afirma que: ${ }^{4}$

A angústia e o terror de abandonar um gênero prescrito ou de passar para o território de outro gênero comprovam as contribuições sociais sobre a interpretação de gênero e a necessidade de haver uma interpretação, isto é, a liberdade essencial na origem do gênero. Do mesmo modo, a generalizada dificuldade em aceitar a maternidade, por exemplo, como realidade institucional e não instintual exprime essa mesma interação de constrição e liberdade. O esforço por interpretar sentimentos maternais como necessidades orgânicas revela um desejo de disfarçar maternidade como uma prática opcional. Se maternidade se torna uma escolha, então o que mais é possível? Esse tipo de questionamento frequentemente causa vertigem e terror ante a possibilidade de perder sanções sociais, de abandonar um lugar e uma posição social sólida. $O$ fato de que esse terror é tão bem conhecido dá o maior crédito à noção de que a identidade de gênero repousa na base instável da invenção humana. ${ }^{5}$

A partir dessa questão, podemos dizer que a maternidade se constitui enquanto produto da cultura, e assume as características atuais da sociedade e do momento que se está vivendo. Esse mesmo conceito de sujeito materno está pautado na lógica construída na modernidade, em que questões de gênero se ancoram a processos que resultam na desigualdade e na hierarquização em meio a modelos sociais que investem na mulher em uma perspectiva que leva em conta uma essência universal e biológica, colocando-a na posição de cuidadora, educadora, 'por natureza', das crianças. ${ }^{\circ}$

Por intermédio das práticas de significação linguística e cultural dos sistemas simbólicos, os significados da maternidade são construídos. Tais significados direcionam as mulheres a um entendimento de sua vivência, compreendendo como se dará a sua prática e seus sentimentos em relação à maternidade. ${ }^{7}$

Desse modo, percebemos que a mulher, na condição de mãe, é uma figura constantemente carregada de sentidos, de valores específicos. A ela é atribuída uma série de 
${ }^{8}$ João Aprigio Guerra de ALMEIDA 1999; Elisabeth BADINTER, 1985; e MEYER, 2003

9 SOCIEDADE BRASILEIRA DE PEDIATRIA, 2009a.

$10 \mathrm{Na}$ segunda edição da Campanha da Amamentação em 2000, houve a confecção de apenas um cartaz para veicular a amamentação ao peito. No intuito de contemplarmos todos os anos em que se tratou da temática, 0 material desse ano também fez parte da presente pesquisa.

${ }^{11}$ BRASIL, 2009.

12 BRASIL, 2010 obrigações e, em muitos casos, é responsabilizada pelo cuidado, saúde e sucesso futuro de seus/as filhos/as. Assim, entendemos que se faz necessário investigar discursos cotidianos, provindos de diferentes lugares, tais como mídia televisiva, jornais, revistas, anúncios e políticas públicas de saúde, que a colocam nesse papel.

As práticas de incentivo ao aleitamento materno, na contemporaneidade, adquirem centralidade em meio a essas questões ${ }^{8}$ e constituem um campo rico de investigação, tendo em vista que a amamentação, no Brasil, é tema de interesse da saúde pública, envolvendo meios de comunicação, governos, comunidades e serviços de saúde em prol de seu incentivo, o que torna a mulher foco de discursos que muitas vezes a posicionam em uma condição exclusivamente voltada à maternidade.

Entendendo as questões postas aqui como de grande importância, em especial na luta contra a desigualdade nas relações de gênero, em que a mulher é submetida a determinados papéis em função de sua anatomia, e tomando, enquanto disparadores, os estudos feministas, que possuem uma aproximação com o pós-estruturalismo, a intenção, com este estudo, é dar visibilidade aos discursos de incentivo ao aleitamento materno, veiculados pelo governo brasileiro em parceria com a Sociedade Brasileira de Pediatria, que circulam no cotidiano das mulheres cujos/as filhos/as estão em período de lactação, haja vista a emergência, cada vez maior, de estudos e ações políticas nas práticas de incentivo à amamentação incididos sobre a mãe.

Sendo assim, elegeram-se para análise desta pesquisa 11 folders e um cartaz que compõem a Campanha da Amamentação, ${ }^{9}$ elaborados pela Sociedade Brasileira de Pediatria (SBP) e confeccionados no período de 1999 a 2010 , com a colaboração do Ministério da Saúde (MS), desde 2004. ${ }^{10}$ Esses mesmos materiais são parte de um importante marketing de mobilização social que tem o intuito de promover o aumento dos índices de aleitamento materno no país. ${ }^{11}$

Por fazerem parte de uma campanha nacional, tais materiais, que também se apresentam no formato de vídeos e propagandas radialistas, são veiculados em diferentes meios de comunicação, como rádio, televisão e sites eletrônicos relacionados ou não ao Ministério da Saúde, e distribuídos em unidades básicas e demais estabelecimentos de saúde de todo o Brasil, incluindo os hospitais. Em 1992, o Ministério da Saúde incorpora a Iniciativa Hospital Amigo da Criança, com o intuito de capacitar profissionais desse campo, realizar avaliações e estimular o credenciamento nesse projeto. Ao receber esse título, o hospital é reconhecido, em seu município, como referência em amamentação. ${ }^{12}$ 
13 Destacamos as palavras "saudáveis" e "equilibrados" em função de entendermos que, frequentemente, a sociedade elege apenas um modo de vida como sendo o mais adequado, estabelecendo, assim, normas $e$ padrões de vivência no cotidiano. Com isso, ela deixa de lado a possibilidade de considerar as diferentes formas de experiencia a realidade.

14 MEYER, 2003, p. 35.

15 Maria Simone Vione SCHWENGBER, 2006.

16 Rosa Maria Bueno FISCHER, 2001a; Michel FOUCAULT, 2007; Guacira Lopes LOURO, 1999; e Alfredo VEIGA-NETO, 2007

17 Félix GUATTARI e Suely ROLNIK, 2008.

${ }^{18}$ MICHEL Foucault, 2007.
Os materiais eleitos para a presente análise se apresentam como uma forma didática e acessível ao público em geral, configurando-se enquanto dispositivos que pretendem atingir as mães brasileiras que possuem crianças em período de lactação, por intermédio da sensibilização em aderir ao aleitamento materno e de uma lista de vantagens e benefícios que se fixam, em especial, na saúde de seus/as filhos/as, colocando-as enquanto principais responsáveis pelo sucesso dessa prática.

A importância da realização de estudos como este se justifica também pelo fato de os movimentos como os da Campanha da Amamentação colocarem a geração e criação de filhos/as 'equilibrados/as' e 'saudáveis'13 como um imperativo, delineando um projeto de vida no qual a muIher que se torna mãe deve se responsabilizar individualmente por essa missão, sem que se leve em conta suas condições sociais e problemas, configurando-se aí uma "nova politização da maternidade". ${ }^{14}$

Esse processo ocorre no Brasil a partir do século XIX, quando a maternidade passa a ser assunto público e a família se torna alvo de investimento em função de dados estatísticos que passam a registrar fenômenos populacionais, tais como nascimentos, mortalidade infantil e natalidade. ${ }^{15}$

Nortearam este estudo as seguintes questões: que 'verdades' e modos de ser mãe estão impressos nesses materiais? De que maneira se apresentam? Que determinados tipos de sujeito querem formar? Qual é a posição ocupada pelo pai em meio aos discursos proferidos? O que significa, para a campanha, cuidar de uma criança?

É válido ressaltar aqui que o sujeito a que se refere o estudo não é um sujeito essencializado, não é algo que está sempre dado. A intenção desta produção é deslocar o olhar do individual para as práticas culturais, entendendo que as pessoas estão localizadas em uma rede discursiva na qual tais práticas são produzidas. Essa produção se constitui em um processo permanente, e o sujeito não participa dele como mero receptor, tendo em vista que está implicado em meio a essa trama, sendo também produtor dela. ${ }^{16}$

Assim, deixamos de lado a ideia de uma natureza humana, apontando para uma subjetividade essencialmente fabricada, modelada, recebida, consumida. Em meio a essa produção da subjetividade, evidencia-se a produção de modos de ser mãe, de ser criança, de ser homem. Em outras palavras, o foco do investimento se dá na produção desses sujeitos, e é por intermédio desse investimento que as pessoas tomam como verdade, consomem determinadas formas de entender a realidade, o mundo, o seu dia a dia e as suas práticas. ${ }^{17}$

Para a análise do material, fizemos uso das ferramentas teórico-metodológicas de Michel Foucault, ${ }^{18}$ levando em 
${ }^{19}$ FISCHER, 1996; 1999; 2001a; e SCHWENGBER, 2006.

${ }^{20}$ FISCHER, 2001a; FOUCAULT, 2007.

${ }^{21}$ FISCHER, 2001a

${ }^{22}$ FISCHER, 2001a

${ }^{23}$ SCHWENGBER, 2006

${ }^{24}$ Silvana Vilodre GOELLNER, 1999 conta seus conceitos de discurso e de enunciado; utilizamonos também das produções que seguem essa mesma linha de investigação. ${ }^{19}$ Desse modo, o discurso é aqui tomado como um conjunto de enunciados que se apoiam em uma mesma formação discursiva. É uma construção histórica, permeada por relações de poder, que se encontram em um determinado campo discursivo e que colocam em funcionamento enunciados e relações. ${ }^{20}$

O enunciado, por sua vez, é uma função de existência que se exerce transversalmente sobre a linguagem, a proposição ou a frase. Ele perpassa um domínio de unidades e de estruturas e permite que estas apareçam temporalmente e espacialmente. Está apoiado em um conjunto de signos, e se caracteriza por quatro elementos, a saber: um referente (um princípio de diferenciação ou, em outras palavras, a referência a algo que identificamos), um sujeito (alguém que afirme o que se profere), um campo associado (associação com outros enunciados do mesmo discurso) e uma materialidade específica (formas concretas com que o enunciado aparece). ${ }^{21}$

As pessoas se sujeitam a determinados discursos quando passam a tomar aquilo que lhes é dito, que lhes é veiculado, enquanto única verdade. As linhas de fuga, nesse caso, são consideradas enquanto maneiras de elas escaparem dessas verdades postas no discurso. Em outras palavras, é preciso que as pessoas se perguntem por que determinadas coisas são ditas de uma forma, em um determinado lugar e momento, e não em outro tempo e lugar, de um modo diferente. ${ }^{22}$

Em função de os materiais que veiculam a prática de amamentação não serem constituídos apenas por textos, consideramos, no processo de análise deste estudo, suas imagens enquanto produtoras de concepções estéticas, políticas e sociais, sendo vistas, portanto, como um texto discursivo e enunciativo que diz, que conta a nossa história atual, uma vez que difundem saberes e valores. ${ }^{23}$

Adotamos essa perspectiva porque entendemos as imagens, representadas nos materiais analisados, enquanto coletivas e individuais. Coletivas porque expressam determinados valores sociais de uma época. Individuais porque também representam o olhar individual de quem as confeccionou, bem como de quem as viu e vê. Desse modo, imagens e textos presentes nos materiais das campanhas dizem sobre os momentos em que foram produzidos, ${ }^{24}$ demonstrando, assim, sua influência na produção dos sujeitos aos quais se destinam. 


\section{Verdades proferidas acerca das práticas maternas: colocando em análise discursos da campanha}

Em meio à proposta lançada pelos materiais analisados ao longo deste estudo, são convidadas a falar, por intermédio da divulgação da amamentação, mulheres famosas, cujos/as filhos/as se encontram em período de lactação. O movimento da campanha permite denotar um sentido valorativo que procura sensibilizar e, ao mesmo tempo, responsabilizar a mãe pelo sucesso da amamentação, proferido por outra figura ali representada: a do/a especialista em saúde da criança. O jogo entre figura e frases introdutórias, sempre estampadas nas capas dos materiais, exerce a função de chamar o/a leitor/a para a importância da amamentação.

Figura 1 - Capa do folder da Campanha da Amamentação de 1999

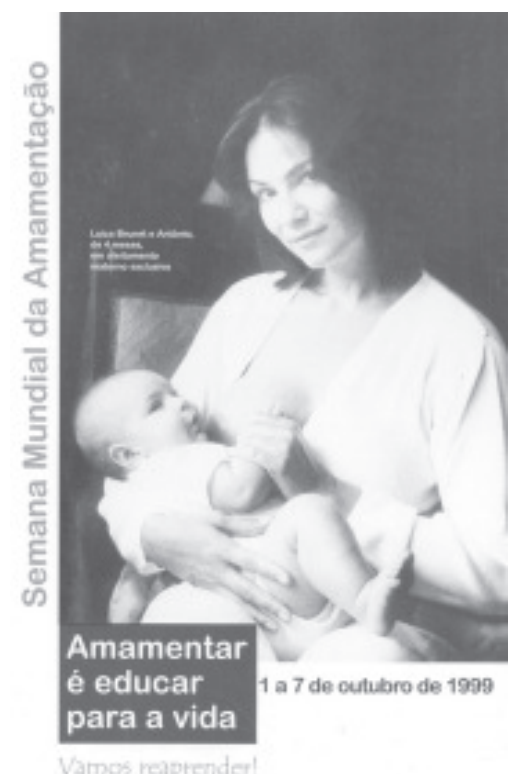

OLEITE MATERENO

É ALINENTO, BAUDEE E ANETO

O sucesso da amamentagso depende

em grande parte do apoie de pediatra

protissionsi mais procurado pelas măes

em situaçoes de dóvida

Vocé esta preparado para wealar o

orientar cma mamada cerreta?

Fonte: SOCIEDADE BRASILEIRA DE PEDIATRIA, 1999.

482 Estudos Feministas, Florianópolis, 22(2): 477-499, maio-agosto/2014 
25 SOCIEDADE BRASILEIRA DE PEDIATRIA, 1999.

26 SOCIEDADE BRASILEIRA DE PEDIATRIA, 1999.

27 FISCHER, 2001b; e Anelise SCHÜTZ, 2003.

${ }^{28}$ SOCIEDADE BRASILEIRA DE PEDIATRIA, 2010a.
O primeiro folder é representado pela atriz Luiza Brunet e seu filho Antônio, de quatro meses, sendo o material um convite feito pela SBP para que as mães e os profissionais da saúde, em especial pediatras, passem a aderir em seu cotidiano ao exercício e também incentivo à amamentação. Nele, a atriz se apresenta amamentando seu filho. Sentada segura o bebê com uma das mãos e, com a outra, acaricia seu braço. Com um leve sorriso, olha para a câmera. A figura é acompanhada por uma série de frases curtas, das quais se destacam as seguintes: "Amamentar é educar para a vida." "Vamos reaprender!" "O leite materno é alimento, saúde e afeto" (Folder, 1999). ${ }^{25}$

O convite para que mães e profissionais da saúde adotem a prática e o incentivo à amamentação, por intermédio dessa introdução da capa, permite amarrar esses enunciados com muitos outros presentes dentro do folder, como aqueles que proferem que o leite materno e o contato inicial com a mãe são fundamentais para o desenvolvimento da criança: "[...] uma educação de qualidade começa nos primeiros momentos após o nascimento, com o aconchego, o calor e a sucção no peito. Este momento é único e repercute por toda a vida" (Folder, 1999). ${ }^{26}$

Esse movimento, no qual profissionais da saúde e mulheres aparecem como figuras de destaque, posiciona sujeitos em meio aos discursos ali proferidos. Por intermédio de sistemas de representação social, que envolvem práticas de significação, e sistemas simbólicos, que permitem a construção desses mesmos significados, criam-se lugares nos quais mulheres, na condição de mães, e profissionais, estampados na figura do/a pediatra, por exemplo, se posicionam e são posicionados e, a partir dos quais, podem falar ou ser falados. ${ }^{27}$

Nesse caso, a figura do especialista aparece na posição de detentor do saber, no que se refere aos benefícios da amamentação e na forma como praticá-la, em um movimento que se inicia na capa e tem prosseguimento ao longo dos materiais, ditando a técnica da mamada correta, como se pode perceber na seguinte frase:

O bebê deve estar virado para a mãe, bem junto de seu corpo, bem apoiado e com os braços livres. A cabeça do bebê deve ficar de frente para o peito e o nariz bem na frente do mamilo. Só coloque o bebê para sugar quando ele abrir bem a boca. Quando o bebê pega bem o peito, o queixo encosta na mama, os lábios ficam virados para fora, o nariz fica livre e aparece mais aréola (parte escura em volta do mamilo) na parte de cima da boca do que na de baixo (Folder, 2010). ${ }^{28}$

A mãe, por sua vez, é posicionada enquanto receptora desse saber, convidada, na figura das atrizes, a proferir o jeito 
${ }^{29}$ FISCHER, $2001 \mathrm{~b}$.

${ }^{30}$ KLEIN, 2007.
32 SOCIEDADE BRASILEIRA DE PEDIATRIA, 2002. certo de exercer sua função materna, desde que se coloque como boa aprendiz da técnica a ela passada. Aqui, engendra-se um movimento que coloca a mulher em uma posição de submissão a um saber que ela não detém, mas que adquire por intermédio do/a especialista, e que nos mostra um exemplo de discurso que nos produz e que produzimos em nossa sociedade. ${ }^{29}$

Isso faz pensar que circulam no dia a dia ideais que fazem as pessoas crer que a mãe é a peça fundamental para o sucesso e para o desenvolvimento das crianças, e, à medida que esses materiais circulam, com o intuito de promover a aderência, por parte das mães, pela prática da amamentação, também constroem sentidos e significados de maternidade. ${ }^{30}$

A técnica da 'mamada correta' é representada em geral por um desenho, no qual o corpo da mulher é fragmentado, dando-se visibilidade apenas para a mama, que se encaixa na boca da criança. O movimento expresso na campanha, quando intencionado a garantir o 'correto' uso da técnica, direciona o foco de atenção para a parte do corpo que ali representa a mulher em sua condição de nutriz. Nesse caso, a preocupação é expressa na forma como a técnica é exercida, sem ao menos dar-se conta que aquele corpo deve ser visto e tratado em sua integralidade.

Em outras palavras, podemos perceber que a imagem enuncia um corpo que tem uma função específica ao gerar uma criança: a de amamentar. Há uma exaltação da mama nessas figuras e nas demais, nas quais as mulheres posam sorridentes para as câmeras e expõem o orgulho do ato de amamentar. Quando as imagens se fixam na demarcação de determinadas partes do corpo, como seios, braços (representando o 'modo correto' de segurar a criança), convidam o/a leitor/a a observar a especificidade delas no cuidado com a criança.

A insistência na forma como se amamenta, ditando aí um padrão específico, demonstra, ainda, que a maternidade é um exercício constante e intensivo, no qual a mãe precisa saber manusear, usar seu corpo em prol da alimentação de seu bebê e, em especial, a mama, parte na qual se situa, nesse caso, a especificidade do exercício da maternagem. ${ }^{31}$

O movimento feito pelos discursos dos demais materiais, no que se refere às frases e às imagens, segue basicamente o mesmo percurso, e se direciona para a representação de um ideal de maternidade, de mãe, e de família, dando um forte sentido de valor para a amamentação, que não se restringe apenas ao ato de alimentar a criança: "Amamentar é dar ao seu bebê saúde em forma de amor" (Folder, 2002). ${ }^{32}$ "Amamentação é uma forma especial de comunicação entre a mãe e o bebê. Ao 
33 SOCIEDADE BRASILEIRA DE PEDIATRIA, 2004 ser amamentada, a criança aprende muito cedo a se comunicar com intimidade, afeto e confiança, o que pode contribuir para a sua saúde mental no futuro" (Folder, 2004). ${ }^{33}$

Figura 2 - Capa do folder da Campanha da Amamentação de 2002.

\section{Amamentar}

é dar ao seu bebê saúde em forma de amor.

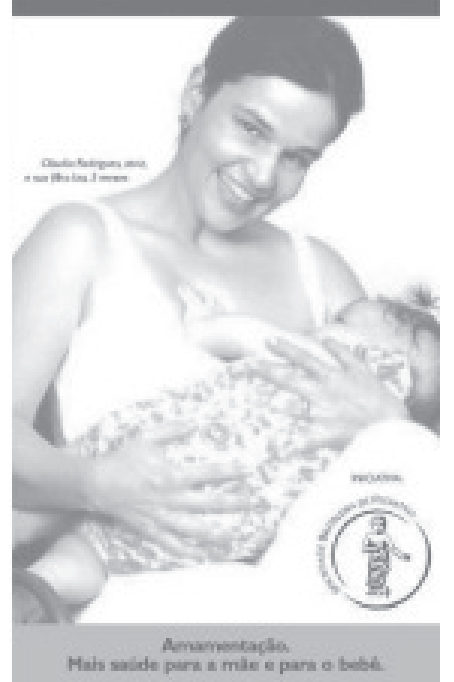

Fonte: SOCIEDADE BRASILEIRA DE PEDIATRIA, 2002.

O sujeito materno é aqui posicionado enquanto aquele que, por intermédio da amamentação, transmite amor e saúde para a criança; mas não é qualquer tipo de saúde: é uma saúde dada em forma de amor. Amamentar, em outras palavras, vem a confirmar a ideia de que uma boa mãe amamenta, pois proporciona à criança muito mais do que alimento. É como se a mãe se doasse para a criança e desse a ela algo único, que o seu próprio corpo produz.

A amamentação, enquanto forma especial de comunicação, indica aqui a presença insubstituível da mãe no processo de desenvolvimento da criança. A cada enunciado presente, repete-se a ideia de que as crianças devem ser cuidadas por suas mães, dando-se a impressão de que estas necessitam ser suas mães biológicas, pois intimidade, afeto, comunicação e aquisição de confiança se expressam através do ato de amamentar ao peito, conforme dita a campanha. Todos esses enunciados presentes nas campanhas estão ligados a um ideal de mãe perfeita, que é a mãe 'natural', noção que se pauta na crença do instinto 
${ }^{34}$ Marizete Argolo TEIXEIRA e Mirian Santos PAIVA, 2006.

${ }^{35}$ SOCIEDADE BRASILEIRA DE PEDIATRIA, 2007.

${ }^{36}$ Aminatta FORNA, 1999.

${ }^{37}$ FORNA, 1999, p. 11.

maternal presente em todas as mulheres: ${ }^{34}$ "Acredite, seu filho prefere seu leite, seu peito, seu colo" (Folder, 2007). ${ }^{35}$

A formulação de um discurso ligado à culpa direcionado àquelas que optam por não amamentar, ou que não conseguem porque praticaram a técnica inadequada - segundo o que se expressa nos folders, basta a mulher acreditar que consegue amamentar para concretizar essa função - é levada aos extremos, quando se dita um futuro, um destino para aqueles/as que são e para aqueles/as que não são amamentados, ligado à sua futura saúde mental. Esse processo de culpabilização vem, mais uma vez, demonstrar que, apesar de proporcionar o entendimento de que a mãe necessita de uma rede de apoio para amamentar, a campanha ainda a coloca como a principal responsável pelo sucesso ou pelo fracasso da prática. Desse modo, como nos apresenta Aminatta Forna: ${ }^{36}$

O mito da maternidade é o mito da 'Mãe Perfeita'. Ela deve ser completamente devotada não só aos filhos, mas a seu papel de mãe. Deve ser a mãe que compreende os filhos, que dá amor total e, o que é mais importante, que se entrega totalmente. Deve ser capaz de enormes sacrifícios. Deve ser fértil e ter instinto maternal, a não ser que seja solteira e/ou pobre, e nesse caso será aviltada precisamente por essas condições. Acreditamos que ela é a melhor, e a única capaz de cuidar corretamente dos filhos, e que eles exigem sua presença contínua e exclusiva. Ela deve incorporar todas as qualidades tradicionalmente associadas à feminilidade, tais como acolhimento, ternura e intimidade. Queremos que ela seja assim e é assim que tentamos fazê-la. ${ }^{37}$

\section{Alimentação, cuidado e educação da criança: 'coisas de mulher'}

As mães que representam a prática da amamentação nas campanhas apresentam-se, na maioria das vezes, sozinhas e, quando acompanhadas, aparecem ao lado de outra mulher (como no caso do folder de $2005,{ }^{38}$ no qual a atriz Maria Paula e sua filha posam ao lado de Vera Viel e seu bebê, ou no caso do folder de $2008^{39}$, em que Dira Paes aparece amamentando seu filho ao lado de sua mãe). 
Figura 3 e 4 - Capas dos folders das Campanhas da Amamentação de 2005 e 2008.

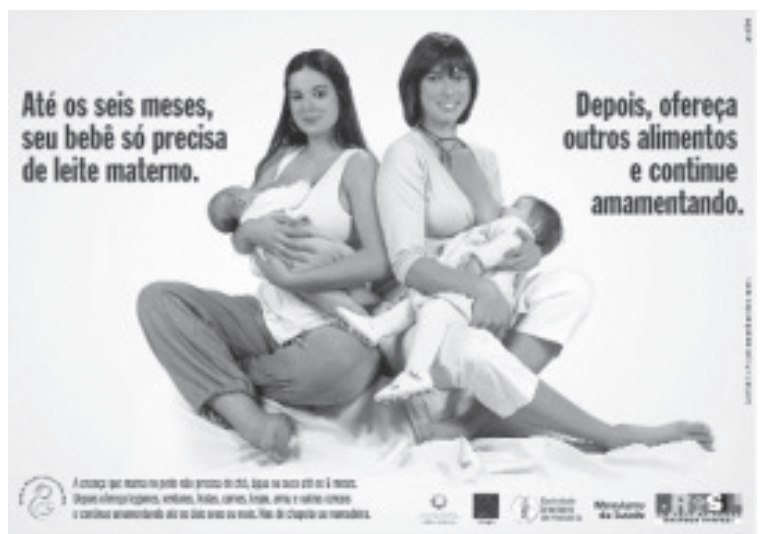

Fonte: SOCIEDADE BRASILEIRA DE PEDIATRIA, 2005 e 2008.

40 SOCIEDADE BRASILEIRA DE PEDIATRIA, 2007.

41 SOCIEDADE BRASILEIRA DE PEDIATRIA, 2002.

42 SOCIEDADE BRASILEIRA DE PEDIATRIA, 2004.

${ }^{43}$ SCHWENGBER, 2006.
O folder de $2007^{40}$ é o único que traz a imagem do pai na capa, acompanhado da mãe e da criança. Os materiais de $2002^{41}$ e de $2004^{42}$ também trazem o pai em meio às imagens, porém, do lado de dentro do folder.

O que enunciam os materiais é que cuidar, nutrir e acompanhar o/a filho/a é basicamente coisa de mulher, em especial porque essa ideia está impregnada por explicações de cunho biológico, nas quais mãe é vista como a cuidadora natural, em função de dar à luz e possuir mamas. A paternidade, nesse caso, é posicionada de forma diferenciada, sendo um acontecimento que se estabelece em um período específico da vida do homem, em um momento que começa com a notícia da gravidez. No caso da mulher, a experiência da maternidade é contínua ${ }^{43}$ e exige dela um preparo para receber o/a filho/a e cuidar dele/a até quando for necessário. Tudo isso fica mais claro quando se foca a atenção para as questões legais de ordem trabalhista que ditam quem tem o direito (ou no caso, o dever) de se afastar do trabalho para cuidar da criança nos seus primeiros meses de vida. Os folders são claros: é preciso divulgar às mães que trabalham seu direito à licença-maternidade de quatro meses, e de duas pausas no trabalho de meia hora cada uma, até os seis meses de vida da criança, para amamentar. Aos pais, reservam-se, por lei, os cinco primeiros dias após o nascimento da criança para que possam permanecer com elas em casa. 
${ }^{44}$ TEIXEIRA e PAIVA, 2006

45 SOCIEDADE BRASILEIRA DE PEDIATRIA, 2008.

46 FORNA, 1999.

${ }^{47}$ FORNA, 1999.
Não é à toa que o movimento da campanha aponta as práticas de cuidado à criança como 'coisa de mulher', tendo em vista que, ao longo dos tempos, as mães e as sogras da nutriz são as principais figuras no incentivo à amamentação. A participação do companheiro, nesse caso, se mostra insignificante, ${ }^{44}$ sendo posicionado como mais um membro da família responsável por apoiar a mãe na prática da amamentação: "Como a família, vizinhos e amigos podem apoiar a amamentação? Ajudando ou assumindo as tarefas domésticas para que as mães tenham tempo e tranqüilidade para amamentar" (Folder, 2008). ${ }^{45}$

Esse movimento feito pela campanha se articula ao posicionamento social dado à mulher: a responsabilidade pelas tarefas da casa, que envolvem o cuidado das crianças e os afazeres domésticos, combinados à sua jornada de trabalho fora do lar. As desigualdades de gênero aumentam à medida que a mãe, expressa na campanha, tem cada vez menos escolhas, tendo em vista que está confinada à sua condição biológica e, portanto, convidada a deixar de lado, ainda que temporariamente, qualquer coisa que a impeça de exercer suas funções maternas.

Para se entender a importância que hoje se dá à relação mãe-bebê e aos aspectos relacionados aos vínculos iniciais, devemos nos remeter aos estudos de Sigmund Freud e de John Bowlby, cujas obras procuraram enfatizar, por intermédio de uma autoridade científica, a necessidade de a mãe dedicar-se exclusivamente aos cuidados das crianças.

Entretanto, não há pretensão aqui de comparar o tempo presente com outros momentos históricos, negando as suas particularidades e a forma singular do modo como emergiam e pulverizavam determinadas verdades. Consideramos, no entanto, que é preciso entender a emergência de determinados discursos e as consequentes modificações culturais que foram consolidando a realidade de hoje.

No início do século XX, Freud já apontava para a ideia de que as experiências primitivas na infância iriam repercutir nos comportamentos posteriores do indivíduo. ${ }^{46}$ Tais teorias propiciaram a disseminação, por parte de seus/as discípulos/ as, de que as mães seriam as culpadas pelos infortúnios de seus/as filhos/as no futuro. Com o psicanalista John Bowlby, a teoria do vínculo e a crescente preocupação dos especialistas com a saúde mental da criança, emerge um movimento que exige a volta, no pós-guerra de 1950, das mães para seus lares, para que ali permanecessem em tempo integral com a criança. ${ }^{47}$

Os estudos de Bowlby tiveram muita influência na vida das mulheres dessa época, em especial porque seus estudos apontavam para os malefícios que os orfanatos propiciavam 
${ }^{48}$ FORNA, 1999.

${ }^{49}$ Fabiana de Amorim MARCELLO, 2005.

${ }^{50}$ FISCHER, 2001b. no desenvolvimento infantil. Ao se fixar na relação mãe-bebê, o autor deixou de considerar que o que acarretava em malefícios para as crianças era, na verdade, a carência das relações humanas existente nesses estabelecimentos. Entretanto, ainda que seus estudos tenham sido muito criticados pela falta de utilização de métodos científicos, tais como os de grupos-controle, eles beneficiaram interesses do Estado, que necessitava reposicionar as mulheres (cujo contexto da guerra as fizeram sair do espaço privado e assumir funções dos homens no mercado de trabalho) com a volta da mão de obra masculina no pós-guerra. ${ }^{48}$

Hoje, o que se percebe é que a mulher, mesmo exercendo uma função fora de casa, ainda é responsabilizada pela criação dos/as filhos/as, cabendo a ela saber administrar essa situação. Em um estudo no qual foram analisadas reportagens de duas revistas de alta circulação no Brasil, no período de 1992 a $2003,{ }^{49}$ os enunciados presentes nos materiais apontam para um movimento em que 'brincadeira de menina' se situa, em especial, no exercício do cuidado com o outro, em gestos que envolvem o embalo das bonecas e demais atitudes que comprovam que essa criança, reduzida ao seu sexo, nasceu para ser mãe.

Quando adulta, é incentivada, segundo os materiais da revista, a deixar de lado o trabalho por um bom tempo, em especial quando resolve ter um/a filho/a logo após o/a outro/a. A ideia se justifica com o trabalho que irá ter no cuidado diário das crianças e no tempo que terá para atender o marido quando este chegar em casa.

Como se pode perceber, a campanha da amamentação se articula a leis, cultura, saberes científicos e, em especial, à mídia, um dispositivo pedagógico que se mostra como local privilegiado na veiculação da informação e educação das pessoas, capturando ainda o/a telespectador/a em sua intimidade, o que o faz, em muitos casos, reconhecer-se em uma série de 'verdades' por ela pronunciadas. ${ }^{50}$

Desse modo, por intermédio de atrizes famosas, veicula um modo de ser mãe, utilizando-se de estratégias que ditam um padrão de mulher já reconhecido (ou, pelo menos, conhecido) pelo público em geral. A mulher que ali representa a mãe brasileira que amamenta não é qualquer mãe, mas sim uma mãe personificada na figura da mulher padrão, com um estilo de vida muitas vezes almejado enquanto modelo ideal.

Entretanto, sabemos que, quando as pessoas padronizam um modo de ser, deixam de lado a possibilidade de produção de outro modo de se pensar a maternidade. Ao ditar um modo de ser mãe, a campanha deixa também de contemplar a realidade de muitas mulheres, como as que possuem um grande número de filhos/as, as que querem ou 
${ }^{51}$ MEYER, 3003

52 SOCIEDADE BRASILEIRA DE PEDIATRIA, 2003. necessitam se inserir no mercado de trabalho porque se encontram na condição de chefes de família, bem como as que não possuem acesso a uma rede de apoio social. ${ }^{51}$

Os materiais ainda traçam um percurso no qual enunciados se entrelaçam em uma demonstração constante de que amamentar é um ato natural e fundamentalmente essencial para a saúde da criança. Não poupam esforços para colocá-lo como uma atitude sublime e cuja função toda mulher é capaz de exercer, como quando ilustram, na campanha de $2003,{ }^{52}$ a atriz Luiza Tomé amamentando seus dois filhos ao mesmo tempo.

Figura 5 - Capa do folder da Campanha da Amamentação de 2003.

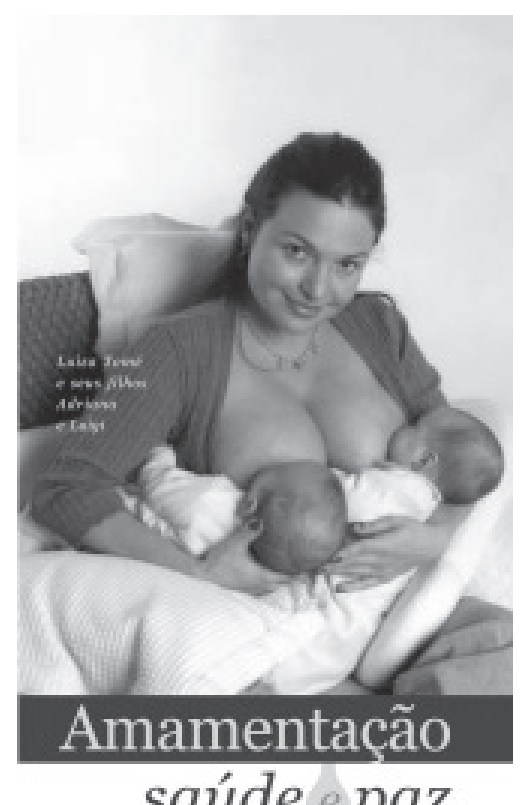

\section{saúde e paz}

para um mando melhor!

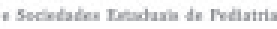

Fonte: SOCIEDADE BRASILEIRA DE PEDIATRIA, 2003.

A imagem, que direciona o olhar do/a leitor/a para as mamas e para a posição 'correta' de amamentar gêmeos corrobora com o movimento que todos os folders fazem ao transmitir a ideia de que, para amamentar, é preciso da técnica aliada à crença, por parte de todos/as e inclusive 
53 SOCIEDADE BRASILEIRA DE PEDIATRIA, 2006.
54 SOCIEDADE BRASILEIRA DE PEDIATRIA, 2003.

55 SOCIEDADE BRASILEIRA DE PEDIATRIA, 2008. da mulher, de que ela pode amamentar: "Acredite, você é capaz de amamentar seu filho!" (Folder 2006). ${ }^{53}$

Entretanto, a figura demonstra que a mãe deve estar rodeada por uma série de instrumentos que lhe possibilitem aleitar seu bebê (como o lugar confortável para se sentar e o ambiente adequado). Sem dúvida, para que Luiza consiga realizar sua função de nutriz de gêmeos, necessita no mínimo da ajuda de outra pessoa, seja para apoiar as crianças junto ao seu corpo, seja para garantir-lhe que, naquele momento, possa fazer aquilo com exclusividade.

O movimento que a campanha faz é o de chamar familiares, amigos e vizinhos, bem como profissionais da área da saúde, para que incentivem e deem apoio às mães nesse momento. Entretanto, os próprios materiais veiculam, em sua maioria, a figura da mulher sozinha no ato da amamentação, demonstrando que, no final das contas, a prática depende quase que exclusivamente dela.

A ideia de que alimentar o/a filho/a com o próprio leite é um ato natural prossegue ao longo dos anos de campanha e é apontada enquanto incumbência única e exclusiva da mulher, que, por intermédio de uma 'verdade' de cunho biológico, é convocada a adotar a prática. Ao mesmo tempo que o exercício da amamentação é constantemente reforçado e apoiado pelo discurso biológico, muitos outros discursos que dão à mãe a incumbência de exercer práticas maternas de um determinado jeito e não de outro demonstram que, para sensibilizá-las, é preciso ligar o aleitamento materno a uma questão de responsabilidade social para com o futuro da nação: "Amamentação, saúde e paz para um mundo melhor!" 54 "Nada mais natural que amamentar. Nada mais importante que apoiar". ${ }^{55}$

Como podemos perceber, as campanhas enunciam que a amamentação está ligada a uma responsabilidade muito grande, por parte das mulheres, com questões que vão além do bom desenvolvimento da criança pequena. Além de garantir uma boa condição de saúde à criança, a amamentação é vista aqui como a solução para muitos problemas que se ligam ao contexto populacional e, no final das contas, dá a ela um status privilegiado.

Sendo um ato considerado natural, passa a ser incumbência de todas as mães cujos/as filhos/as estão em período de lactação e, sendo ligado à garantia de um futuro melhor para a população, cabe à mãe aderir ao processo como todas as outras que assim o fizeram e que demonstram, por intermédio dos materiais, que isso é possível.

Hoje, uma série de especialistas da área da saúde, um dos muitos agentes autorizados a proferir 'verdades' sobre o tema da maternidade, lançam receitas e modos adequados de ser, apontando para os malefícios para a criança 
${ }^{56}$ Ana Paula ACAUAN, 2010.

${ }^{57}$ ACAUAN, 2010, p. 16.

${ }^{58}$ UOL NOTÍCIAS, 2010 quando a mãe não adere aos pressupostos da ciência. Algumas dessas 'verdades' se manifestam na entrevista dada pelo pediatra Jorge César Martínez à revista PUCRS Informação:56

\begin{abstract}
Temos em nossas mãos o futuro de uma pessoa. O que fazemos ou deixamos de fazer vai favorecer que esse ser humano cresça sadio física e mentalmente. Os filhos dependem grande parte de nós. É uma incrível oportunidade. Que outra parte do corpo podemos com nossas ações modificar? Nenhuma. Com meu comportamento eu vou fazer que essa pessoa seja saudável mentalmente. Que esse indivíduo não use sua inteligência para produzir bombas, atentados [...]. Acredito nas mães. Elas podem trabalhar os filhos desde recém-nascidos, que têm a chance de aprenderem a lidar com as situações sem violência. Que as mães não trabalhem por três anos. Estão criando o futuro brasileiro, argentino, canadense. Sou um sonhador. A cada três, cinco, 200 gerações, poderemos mudar. Falamos inglês, português, espanhol. A mãe fala o idioma do coração. ${ }^{57}$
\end{abstract}

Aqui, problematizamos a questão, apontando para diferentes discursos, pautados em uma autoridade científica, que são lançados às mulheres e também aos homens. Ainda que se reconheça a importância da amamentação para o desenvolvimento da criança, é preciso entender que a forma como se veiculam as práticas de cuidado expressa a grande influência que a cultura contemporânea, especialmente na realidade brasileira, promove sobre as atitudes das mães, ditando-lhes o que fazer, como fazer, o que devem sentir por seus/as filhos/as e quais são os limites entre o normal e o patológico nessa relação.

As mães são convidadas a salvar o futuro da nação, a deixar de lado seus empregos, negociar com sua chefia, readaptar sua rotina em prol do desenvolvimento da criança, mas cada vez menos se pergunta a elas o que pensam disso e como fazem para tornar essa realidade possível.

Em uma entrevista à revista alemã Spiegel, em 30 de agosto de 2010, reproduzida no site UOL, ${ }^{58}$ Elisabeth Badinter aponta para seu temor de que um novo discurso de retorno à natureza esteja fazendo com que muitas mulheres abandonem suas lutas e conquistas em prol de sua emancipação para aderirem aos valores de suas avós. O desejo de que a criança seja perfeita é apontado por ela como consequência desse movimento, e o esforço da mulher em ficar em casa cuidando pessoalmente dos/as filhos/as vem justamente ao encontro desse objetivo.

Para a filósofa, as mães sofrem uma pressão muito grande para amamentar seus/as filhos/as, prática essa que, em sua opinião, envolve decisões muito pessoais que só 
${ }^{59}$ SCHWENGBER, 2009.

60 SOCIEDADE BRASILEIRA DE PEDIATRIA, 2007.

${ }^{61}$ MEYER, 2003.

${ }^{62}$ Georges CANGUILHEM, 2002, p. 156. dizem respeito à mulher. Entretanto, o assunto acabou virando uma das prioridades na agenda da Organização Mundial da Saúde, misturando-se a questões de ordem política e econômica. Mais do que nunca, e na medida em que a reprodução ganhou visibilidade para além do contexto familiar, ela passou a ser regulada e vigiada, o que, por sua vez, colocou a mulher enquanto figura central em meio ao processo de gestação, do aleitamento, do cuidado e da educação das crianças. ${ }^{59}$

A exemplo de como a Campanha de Amamentação se constitui em um mecanismo regulador da vida das mães, trazemos para esta discussão o movimento unânime de todos os folders na determinação do tempo em que se deve amamentar: de forma exclusiva até os seis meses de vida da criança, sem a utilização de águas, chás, e, após os seis meses, administrada juntamente com outros alimentos, até os dois anos ou mais. No sentido de informar às mães e aos demais leitores desses folders sobre a importância de amamentar até esse período, muitos materiais proferem: "O leite humano é o único alimento capaz de oferecer todos os nutrientes na quantidade exata de que o bebê precisa. Ele garante o melhor crescimento e desenvolvimento, não existindo nenhum outro alimento capaz de substituí-lo". 60

Percebemos que se expressa, em meio aos materiais analisados, um conjunto de enunciados que atribuem à saúde da criança em geral (seu desenvolvimento físico, afetivo e cognitivo) determinados comportamentos e formas de cuidado que, mesmo com os avanços tecnológicos e dos movimentos feministas, colocam a maternidade como uma tarefa muito difícil e abrangente, tendo como exemplo claro disso a forma como a prática do aleitamento materno é hoje concebida e ditada no Brasil. ${ }^{6}$

Assim, a Campanha de Amamentação acaba ditando um padrão de normalidade em relação às práticas maternas. Para Georges Canguilhem, há uma imprecisão no que se refere ao limite entre o normal e o patológico. Tudo aquilo que se taxa de 'anormal', na verdade, é assim nomeado porque se apresenta enquanto diferente daquilo que se está acostumado. Ao se criar uma norma, uma lógica de normalidade, esquece-se que "[...] não há desordem, há substituição de uma ordem esperada ou apreciada por uma outra ordem que de nada nos serve e que temos que suportar". ${ }^{62}$ As palavras do referido autor fazem refletir o quanto os processos de resistência de muitas mulheres, no que se refere à prática da amamentação, da forma como é veiculada, acabaram, de certo modo, sendo enquadradas, por intermédio da campanha da amamentação, em um viés psicopatológico a favor de uma norma preestabelecida, na qual quem não amamenta não é normal. 
63 SOCIEDADE BRASILEIRA DE PEDIATRIA, 2008.

${ }^{64}$ Lutiane de LARA, 2009.
Assim, as mães que optam por não amamentar são apontadas, em meio às campanhas analisadas, em uma lógica de anormalidade, e à população em geral cabe passar à nutriz apenas experiências que condigam com o que ditam as 'verdades' expressas nos materiais: "Como a família, vizinhos e amigos podem apoiar a amamentação? Transmitindo experiências positivas de aleitamento materno" (Folder 2008). ${ }^{63}$ Podemos pensar que, se é recomendado a uma mãe que ela ouça apenas o que as pessoas têm de positivo para falar sobre o aleitamento materno, é porque nem toda experiência é válida para a campanha.

E quando o que os materiais veiculam é tomado como discurso de verdade, incide-se também na produção de um determinado tipo de infância, bem como de maternidade, colocando-se acima dos saberes que a sociedade tem sobre saúde da criança. Apesar de ajudarem a orientar as pessoas a como proceder em relação a alguns aspectos do cotidiano, que envolvem o bem-estar da criança, esses materiais também desqualificam a família e a sociedade em geral ao desconsiderarem seus conhecimentos. ${ }^{64}$

Na campanha, há um padrão de mãe estabelecido, no qual a noção de maternidade desviante não aparece, mas se faz presente na grande insistência pela aderência da amamentação como forma de cuidado com a saúde da criança. Não aderir a tudo o que ela preconiza implica colocar a vida do bebê em risco ou não lhe proporcionar uma boa aparência nos dentes com o uso, por exemplo, de chupetas e mamadeiras, que, além de serem consideradas fonte de prejuízo para a saúde (fala e respiração), não contribuem para a formação de uma arcada dentária bonita. Isso tudo se liga, em meio aos materiais, a informações incisivas acerca dos benefícios da amamentação ao peito, demonstrando que a criança representada na campanha necessita possuir um peso padrão e ter determinadas características físicas que a ligam à figura de um ser saudável e bonito. Assim, o exercício da maternidade é ligado à responsabilidade pelo desenvolvimento de uma pessoa 'saudável' físico, cognitivo e emocionalmente, ${ }^{65}$ havendo aí um ideal de saúde que se configura nos moldes de como a mãe exerce sua função.

Assim, o valor de verdade impresso nos discursos científicos de cunho médico e psicológico que ligam a saúde do indivíduo ao ato de ser amamentado, em meio às campanhas de amamentação brasileiras, acaba produzindo determinados tipos de criança: a que mamou no peito e a que não mamou, bem como de mãe: a que amamenta, a que não amamenta porque não quer e a que não amamenta porque não pode. Tudo isso posiciona mulheres e crianças nas redes de vigilância e de controle

494 Estudos Feministas, Florianópolis, 22(2): 477-499, maio-agosto/2014 
${ }^{66}$ MEYER, 2003

${ }^{67}$ FOUCAULT, 1979.

${ }^{68}$ Anita Guazzelli BERNARDES e Dionatans Godoy QUINHONES, 2009.

69 BERNARDES Q QUINHONES, 2009 . nos sistemas de saúde, colocando-as em grupos considerados normais ou de risco. 66

\section{Wanessa, uma brasileira como tantas...}

Ao longo dos 12 anos de campanha no Brasil, percebe-se a construção e a perpetuação de enunciados que posicionam a mãe como insubstituível no cuidado da criança. Os materiais da campanha, ao investirem na educação delas, transformando-as em sujeitos de cuidado, mostram-se como tecnologias de governo, exercícios existentes no dia a dia que ordenam a vida por intermédio de sentidos referentes ao modo que cada um tem que viver. Tudo isso se denomina arte de governo, tendo em vista que essa prática não se estabelece de forma proibitiva, mas na forma de controle, de administração. ${ }^{67}$

Entretanto, ao se prescrever formas específicas de cuidado, elegendo a mãe como a que melhor desempenha essa função, deixa-se de lado todas as demais possibilidades de relação que a criança poderia estabelecer com outros possíveis cuidadores. A família exerce aqui um papel secundário, e a dupla mãe-bebê ganha centralidade nesses discursos, em uma lógica de causa e efeito na qual amamentar e cuidar pessoalmente da criança pode selar seu destino, alcançando a saúde ou a doença.

A ideia da promoção da saúde segue outro viés, deixando de lado intervenções nas quais a saúde é tomada como estratégia de controle da vida (formas de governo) para se atentar às diversas possibilidades de modos de vida, nas quais estão incluídas a solidariedade, a cidadania e a equidade. Quando o cuidado é destinado ao tratamento, à prevenção e à reabilitação, as práticas de saúde se colam à prescrição, as práticas de governo ditam como se deve viver para, assim, obter uma boa saúde. ${ }^{68}$

O ponto que direciona tais estratégias é a própria doença, que demarca as ações na busca da saúde. A promoção da saúde é lançada dentro de uma proposta que inclui outras formas de vida, compreendendo a diversidade dos diferentes modos de vivenciar a realidade, dando abertura para a invenção, para os afetos, desejos e experiências singulares. ${ }^{69}$

Assim, finalizamos esta discussão colocando em questão o pronunciamento feito pela SBP ao longo da divulgação da campanha de 2010, na qual foi eleita para ser madrinha da campanha uma mãe 'diferente' daquelas que até então representavam o movimento em prol da amamentação, tendo como novidade o fato de a madrinha desse mesmo ano não ser famosa, característica esta presente nos outros 11 anos de campanha. 
70 SOCIEDADE BRASILEIRA DE PEDIATRIA, 2010b.

71 SOCIEDADE BRASILEIRA DE PEDIATRIA, 2010b.
Wanessa, anunciada como "uma brasileira como tantas", ${ }^{70}$ foi apontada enquanto cidadã cuja história muito se aproximava das demais mulheres do país: uma gravidez, o nascimento da filha, o problema de uma fissura na mama com consequente aconselhamento dado por familiares para dar à criança a chupeta, e o incentivo de um Hospital Amigo da Criança para que permanecesse amamentando. Mais uma vez, encontramos aqui a valorização, a exaltação impressa na figura da mãe que persiste na amamentação, em especial por deixar de lado os conselhos alheios e por seguir à risca as normas ditadas pelo saber dos/as profissionais.

A forma como a SBP posiciona Wanessa em meio à divulgação da campanha faz refletir ainda como se mostram os sentidos valorativos que permeiam as ações de quem rege a saúde do país: "Muitas mulheres famosas já cederam sua imagem à campanha, mas desta vez é uma usuária do Sistema Único de Saúde (SUS)". ${ }^{71}$

Ainda que se saiba que todos/as nós somos usuários/ as do SUS, a afirmação acima parece colocar as mães brasileiras em posições diferentes em relação aos serviços de saúde oferecidos pelo país. Se até então as capas dos materiais analisados neste estudo foram representadas por imagens de mulheres famosas, por que somente na última campanha, representada por uma 'brasileira comum', se dá evidência à madrinha enquanto usuária do SUS? Não seriam as outras também usuárias desse sistema? Seriam as atrizes famosas que posaram para as campanhas anteriores exemplos, modelos de mães para as 'reais' usuárias do SUS?

O que se pode perceber é que a Campanha da Amamentação está formulada e direcionada para um modelo específico de mãe que, na maioria das vezes, não contempla a realidade de todas as brasileiras, cujas atitudes a campanha quer regular em meio às práticas maternas. $\mathrm{A}$ mãe dos materiais analisados está resumida na figura da mulher casada, que mantém um relacionamento heterossexual, usuária de um serviço de saúde ainda não reconhecido como sendo para todos/as, cujas escolhas são regidas por especialistas que detêm a fórmula 'certa' e 'adequada' de como produzir cidadãos e cidadãs saudáveis.

\section{Referências}

ACAUAN, Ana Paula. "Só as mães podem salvar o mundo: pediatra destaca que o cuidado com os bebês tem a incrível possibilidade de moldar o futuro". PUCRS Informação, Porto Alegre, n. 150, p. 16, jul./ago. 2010.

ALMEIDA, João Aprigio Guerra de. Amamentação: um híbrido natureza-cultura. 20. ed. Rio de Janeiro: Fiocruz, 1999. 
ALMEIDA, João Aprigio Guerra de; NOVAK, Franz Reis. "Amamentação: um híbrido natureza-cultura". Jornal de Pediatria, v. 80, n. 5, p. 119-125, nov. 2004.

BADINTER, Elisabeth. Um amor conquistado: o mito do amor materno. 8. ed. Rio de Janeiro: Nova Fronteira, 1985.

BERNARDES, Anita Guazzelli; QUINHONES, Dionatans Godoy. "Práticas de cuidado e produção de saúde: Formas de governamentalidade e alteridade". Psico, v. 40, n. 2, p. 153-161, abr./jun. 2009.

BRASIL. Ministério da Saúde. Promoção, Proteção e Apoio ao Aleitamento Materno. Brasília, 2009. Disponível em: <http://portal.saude.gov.br/portal/saude/ area.cfm?id_area $=1460>$. Acesso em: 24 out. 2009.

BRASIL. Ministério da Saúde. Iniciativa Hospital Amigo da Criança. Brasília, 2010. Disponível em: <http:// portal.saude.gov.br/portal/saude/ visualizar_texto.cfm?idtxt=24229>. Acesso em: 20 out. 2010.

BUTLER, Judith. "Variações sobre sexo e gênero: Beauvoir, Wittig e Foucault." In: BENHABIB, Sheila; CORNELL, Drucilla (Coords.). Feminismo como crítica da modernidade. Rio de Janeiro: Rosa dos Tempos, 1987. p. 139-154.

CADONÁ, Eliane. Amamentar é educar para a vida?!?!: A produção da maternidade contemporânea nas campanhas da amamentação. 2010. Dissertação (Mestrado em Psicologia Social) - Programa de PósGraduação em Psicologia, Faculdade de Psicologia da PUCRS, Porto Alegre.

CANGUILHEM, Georges. O normal e o patológico. 5. ed. Rio de Janeiro: Forense Universitária, 2002.

COLLING, Ana Maria. "O corpo que os gregos inventaram". In: STREY, Marlene Neves; CABEDA, Sônia Lisboa (Orgs.). Corpos e subjetividades em exercício interdisciplinar. Porto Alegre: EDIPUCRS, 2004. p. 49-64.

FISCHER, Rosa Maria Bueno. Adolescência em discurso: mídia e produção de subjetividade. 1996. Tese (Doutorado em Educação) - Programa de Pós-Graduação em Educação, Faculdade de Educação da UFRGS, Porto Alegre.

"Foucault e o desejável conhecimento do sujeito". Educação \& Realidade, v. 24, n. 1, p. 39-59, jan./jun. 1999. . "Foucault e a análise do discurso em educação". Cadernos de Pesquisa, n. 114, p. 197-223, nov. 2001a. "Mídia e educação da mulher: uma discussão teórica sobre modos de enunciar o feminino na TV". Revista Estudos Feministas, v. 9, n. 2, p. 586-599. 2001 b. FORNA, Aminatta. Mãe de todos os mitos: como a sociedade modela e reprime as mães. Rio de Janeiro: Ediouro, 1999.

FOUCAULT, Michel. Microfísica do poder. 10. ed. Rio de Janeiro: Edições Graal, 1979. 

2007.

A arqueologia do saber. 7. ed. Rio de Janeiro: Forense,

GOELLNER, Silvana Vilodre. Bela, maternal e feminina: imagens da mulher na Revista Educação Physica. 1999. Tese (Doutorado em Educação) - Programa de PósGraduação em Educação, Faculdade de Educação da Universidade Estadual de Campinas, Campinas.

GUATTARI, Félix; ROLNIK, Suely. Micropolítica: cartografias do desejo. 9. ed. Petrópolis: Vozes, 2008.

KLEIN, Carin. "Educação, maternidade e política cultural". Gênero, v. 7, n. 2, p. 171-194, 2007.

LARA, Lutiane de. Saúde pública e saúde coletiva: investindo na criança para produção de cidadania. 2009. Dissertação (Mestrado em Psicologia Social) - Programa de Pós-Graduação em Psicologia, Faculdade de Psicologia da PUCRS, Porto Alegre.

LOURO, Guacira Lopes. "Pedagogias da sexualidade”. In: LOURO, Guacira Lopes. (Org). O corpo educado: pedagogias da sexualidade. Belo Horizonte: Autêntica, 1999. p. 7-34.

MARCELLO, Fabiana de Amorim. "Dispositivo da maternidade: mídia e a produção pedagógica de sujeitos, práticas e normas". Educar, n. 26, p. 81-98, 2005.

MEYER, Dagmar E. "As mamas como constituintes da maternidade: uma história do passado?". Educação \& Realidade, v. 25, n. 2, p. 117-133, jan./jun. 2000.

"Educação, saúde e modos de inscrever uma forma de maternidade nos corpos femininos". Movimento, v. 9, n. 3, p. 33-58, set./dez. 2003.

PAIM, Maria Cristina Chimelo; STREY, Marlene Neves. "Corpos em metamorfose: um breve olhar sobre os corpos na história, e novas configurações de corpos na atualidade". Lecturas: EF y Deportes, v. 10, n. 79, Dic. 2004.

SCHÜTZ, Anelise. "Relações entre amamentação, inteligência e aproveitamento escolar: uma problematização a partir dos Estudos de Gênero". In: SEMINÁRIO INTERNACIONAL EDUCAÇÃO INTERCULTURAL, GÊNERO E MOVIMENTOS SOCIAIS: IDENTIDADE, DIFERENÇAS, MEDIAÇÕES, 2., 2003, Florianópolis. Anais... Florianópolis, 2003. Não paginado.

SCHWENGBER, Maria Simone Vione. Donas de si? Educação de corpos grávidos no contexto da Pais \& Filhos. 2006. Tese (Doutorado em Educação) - Programa de PósGraduação e, Educação, Faculdade de Educação da UFRGS, Porto Alegre.

"A educação da mãe carinhosa e o discurso das práticas corporais e esportiva nas páginas da Pais \& Filhos". Movimento, v. 15, n. 3, p. 209-232, 2009.

SOCIEDADE BRASILEIRA DE PEDIATRIA. Folder da Campanha da Amamentação. 1999. 
- Cartaz da Campanha da Amamentação. 2000. . Cartaz da Campanha da Amamentação. 2001. . Cartaz da Campanha da Amamentação. 2002. - Cartaz da Campanha da Amamentação. 2003. . Cartaz da Campanha da Amamentação. 2004. . Cartaz da Campanha da Amamentação. 2005. - Cartaz da Campanha da Amamentação. 2006. - Cartaz da Campanha da Amamentação. 2007. - Cartaz da Campanha da Amamentação. 2008. - Cartaz da Campanha da Amamentação. 2009. - Cartaz da Campanha da Amamentação. $2010 a$.

"Madrinha da campanha de amamentação, Wanessa é uma brasileira como tantas". 2010. Disponível em: <http:/ /www.sbp.com.br/show_item2.cfm?id_categoria = 89\&id detalhe $=3612 \&$ tipo detalhe $=s>$. Acesso em 28 nov. 2010b.

TEIXEIRA, Marizete Argōlo; PAIVA, Mirian Santos. "A influência das questões de gênero no processo de amamentação". In: SEMINÁRIO INTERNACIONAL FAZENDO GÊNERO, 7., 2006, Florianópolis. Anais... Florianópolis: Ed. Mulheres, 2008.

UOL NOTÍCIAS. "Mulheres não são chimpanzés", diz Elisabeth Badinter. Disponível em: <http://noticias.uol.com.br/ midiaglobal/derspiegel/2010/08/30/mulheres-nao-saochimpanzes-diz-elisabeth-badinter.jhtm > . Acesso em: 30 ago. 2010.

VEIGA-NETO, Alfredo. Foucault \& a Educação. 2. ed. Belo Horizonte: Autêntica, 2007.

WELZER-LANG, Daniel. "A construção do masculino: dominação das mulheres e homofobia". Revista Estudos feministas, v. 9, n. 2, p. 460-482. 2001.

[Recebido em abril de 2011, reapresentado em junho de 2013 e aceito para publicação em março de 2014]

\section{Production of Maternity in Breastfeeding Incentive Discourses}

Abstract: In this article we study several materials from the Breastfeeding Campaign, and discuss practices of incentive to breastfeeding in contemporaneity by observing how those materials disclose the roles of a mother, a father and how children should be nursed. For data analysis, we used Michel Foucault's concepts of discourse and statement, taking them as theoretical and methodological tools. In the materials, we realized the mother is held as the chief responsible for the health of her children, being her duty to take care of the children and nurture them. The father plays a secondary role in this relationship. It is when the medical professional stands out, appointed as the holder of the knowledge about breastfeeding practices, so that the mother must adhere to the expertise in favor of her child's health.

Key Words: Maternity; Paternity; Discourse; Breastfeeding. 